http://dx.doi.org/10.18675/1981-8106.vol25.n48.p99-113

\title{
Mudanças no ensino de gramática/análise linguística: com a palavra, os professores
}

\author{
Changes in the teaching of grammar / linguistic analysis: with the word, the \\ teachers
}

\section{Cambios en la enseñanza de gramática/análisis lingüístico: con la palabra, los professores}

\author{
Alexsandro da Silva ${ }^{\prime}$ \\ ' Universidade Federal de Pernambuco (UFPE), Pernambuco - Brasil. E-mail: alexs-silva@uol.com.br
}

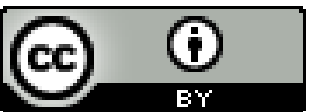

Educação: teoria e prática, Rio Claro, SP, Brasil - eISSN: 1981-8106

Está licenciada sob Licença Creative Common

\section{Resumo}

O artigo apresenta resultados de um estudo que teve como objetivo analisar mudanças nas práticas de ensino de gramática/análise linguística de professores dos anos iniciais do ensino fundamental. Para isso, apoiamo-nos em referenciais ligados não apenas ao ensino de gramática/análise linguística, mas também aos saberes e às práticas docentes. A proposta metodológica, que se inscreveu em uma abordagem qualitativa, utilizou como procedimento metodológico a entrevista semiestruturada, a qual foi realizada com professores de $4^{\circ}$ e $5^{\circ}$ anos do ensino fundamental de escolas públicas de cidades do interior do estado de Pernambuco - Brasil. A partir do suporte da análise temática de conteúdo, percebemos, nas falas desses professores, que, para eles, as mudanças em suas práticas de ensino de gramática/análise linguística relacionavam-se, principalmente, a dois aspectos: a utilização de textos e o uso não exclusivo do livro didático. Todavia, os depoimentos dos docentes revelaram que tais mudanças não substituíam, inteiramente, as antigas maneiras de ensinar gramática, mas evidenciavam um complexo processo no qual se articulavam mudanças e permanências.

Palavras-chave: Mudanças no ensino de língua; Ensino de gramática; Análise linguística. 


\begin{abstract}
The article presents a study that aimed to examine changes in practices of teaching grammar I linguistic analysis of teachers of early elementary school years. For this, we rely on references linked not only to grammar teaching/linguistic analysis, but also knowledge and teaching practices. The methodology, which was inscribed on a qualitative approach, used as a methodological procedure the semi-structured interview, which was conducted with teachers from public schools in the inner cities of the state of Pernambuco-Brazil. From the support of thematic content analysis, we realize, based on the words of those teachers that, for them, the changes in their teaching grammar / linguistic analysis were related mainly to two aspects: the use of texts and the non-exclusive use of the textbook. However, the testimonies revealed that such changes did not entirely replace the old ways of teaching grammar, but evidenced a complex process in which changes and continuities were articulated.
\end{abstract}

Keywords: Changes in language teaching; Teaching grammar; Linguistic analysis.

\title{
Resumen
}

El artículo presenta resultados de un estudio que tuvo como objetivo analizar los cambios en las prácticas de enseñanza de gramática/análisis lingüística de profesores de los años iniciales de la enseñanza fundamental. Para eso, nos apoyamos en referenciales relacionados no apenas a la enseñanza de gramática/análisis lingüística, sino también a los saberes y a las prácticas docentes. La propuesta metodológica, que se inscribió en un abordaje cualitativo, utilizó como procedimiento metodológico la entrevista semiestructurada, que se realizó con profesores de $4^{\circ}$ y $5^{\circ}$ años de la enseñanza fundamental de escuelas públicas de ciudades del interior del estado de Pernambuco - Brasil. A partir del soporte del análisis temático de contenido, notamos, en las hablas de esos profesores que, para ellos, los cambios en sus prácticas de enseñanza de gramática/análisis lingüístico se relacionaban, principalmente, a dos aspectos: la utilización de textos y el uso no exclusivo del libro didáctico. Sin embargo, los testimonios de los docentes revelaron que tales cambios no sustituían, completamente, las antiguas maneras de enseñar gramática, sino que evidenciaban un complejo proceso en el que se articulaban cambios y permanencias.

Palabras clave: Cambios en la enseñanza de lengua; Enseñanza de gramática; Análisis lingüístico. 


\section{Introdução}

São inúmeros, no Brasil, os estudos (MATTOS E SILVA, 1997; NEVES, 2003, 2012; MORAIS, 2002; MENDONÇA, 2006) que têm apontado críticas ao ensino de gramática centrado em exercícios estruturais de reconhecimento e classificação de palavras, frases ou períodos e na transmissão de regras gramaticais, muitas delas distantes dos atuais usos linguísticos dos brasileiros. Apesar dessas críticas, o ensino de gramática praticado nas escolas parece ter pouco se alterado, ao longo do tempo.

Essa permanência, que, muitas vezes, é explicada, de modo simplista, como uma mera resistência dos professores às inovações, evidencia, na realidade, que as mudanças nas práticas de ensino não ocorrem como resultado de uma transposição didática direta de mudanças produzidas no campo teórico. Em outras palavras, os professores não recebem passivamente as informações a que têm acesso, mas antes, as selecionam e as transformam, tomando como critério a sua pertinência às ações que desenvolve em sala de aula.

Com base nessa discussão, efetivamos uma investigação que teve como objetivo analisar mudanças nas práticas de ensino de gramática/análise linguística desenvolvidas por professores dos anos iniciais do ensino fundamental. Tendo em vista este objetivo, discutimos, inicialmente, questões ligadas, por um lado, ao ensino de gramática/análise linguística e, por outro, aos saberes e às práticas de ensino dos professores. Em seguida, após apresentarmos os aspectos metodológicos do estudo, discutimos os principais resultados da pesquisa e apresentamos algumas considerações finais.

\section{Ensino de língua portuguesa: das aulas de gramática às práticas de análise linguística}

No contexto brasileiro, desde o início da década de 1980, uma nova maneira de conceber a linguagem começou a se estabelecer. Nessa nova concepção, a linguagem seria vista como uma forma de interação social e não simplesmente como um código ou instrumento de comunicação (GERALDI, 2003). Como esclarece Soares (1998, p.59), trata-se de "uma concepção que vê a língua como enunciação, discurso, [...] que, portanto, inclui as relações da língua com aqueles que a utilizam, com o contexto em que é utilizada, com as condições sociais e históricas de sua utilização".

Ancorado nessa concepção de linguagem como interação, Geraldi (2003, p.74) propôs a "prática de análise linguística" como um dos eixos das aulas de português, as quais seriam organizadas por meio da articulação entre as práticas de leitura, produção de textos e análise linguística. Segundo esse autor, essa nova expressão - análise linguística - não era, no entanto, apenas um novo rótulo para o antigo ensino de gramática, pois ela incluiria "tanto o trabalho sobre questões tradicionais da gramática quanto questões mais amplas a propósito do texto". 
Sobre o termo análise linguística, Mendonça (2006, p. 205) esclarece que ele surgiu para designar "uma nova perspectiva de reflexão sobre o sistema linguístico e sobre os usos da língua, com vistas ao tratamento escolar de fenômenos gramaticais, textuais e discursivos". Essa autora ressalta, ainda, que a análise linguística não exclui a gramática das aulas de português, mas adverte que os estudos gramaticais ocorrem a partir de objetivos distintos e no quadro de outro paradigma.

No campo do currículo, assistimos, no Brasil, diversas tentativas - ainda que com contradições e distorções - de aproximação das propostas curriculares às novas perspectivas divulgadas nos discursos acadêmico-científicos, conforme constatou Marinho (1998), ao analisar currículos de língua portuguesa do ensino fundamental das décadas de 80/90 do século XX de dezenove estados brasileiros.

Segundo essa autora, essas propostas curriculares criticavam o ensino tradicional de português, sugerindo, de modo geral, um deslocamento da gramática para o texto e assumindo, muitas vezes, um novo nome para a seção relativa à gramática, que passou a ser chamada de conhecimentos linguísticos. No entanto, conforme os resultados daquele estudo, a gramática ocupava lugares diferentes nos diversos currículos, não sendo essa posição exclusiva.

Como decorrência desse processo de mudança, temos vivido, também, nos últimos anos, no contexto brasileiro, um processo de melhoria significativa dos livros didáticos. Segundo Costa Val e Castanheira (2005), entre 1998 e 2004, observou-se uma diminuição do número de obras não aceitas e um aumento gradativo de obras aprovadas, na área de Alfabetização e Língua Portuguesa, no Programa Nacional do Livro Didático (PNLD) ${ }^{1}$.

Ao analisarem os resultados da avaliação dos livros didáticos de língua portuguesa do PNLD 2004, no que concerne ao trabalho voltado para os conhecimentos linguísticos, as autoras supracitadas constataram, todavia, uma tendência de permanência da tradição gramatical, com altos índices relativos a conhecimentos morfológicos, semânticos (sinonímia, antonímia, paronímia e homonímia), morfossintaxe, fonologia e ortografia, e uma baixa frequência de atividades voltadas ao texto e ao discurso.

Em meio a essas novas perspectivas, que não são inequívocas, mas marcadas por ambiguidades, os docentes se veem diante do imperativo de mudança de suas práticas de ensino de gramática, as quais tenderiam a permanecer centradas, sobretudo, no estudo de nomenclaturas e de classificações. Essa constatação precisa, no entanto, ser matizada pelo fato de que os professores não estão inertes ante as novas perspectivas para o ensino de língua materna, ainda que as apropriações que eles façam delas não se coadunem, muitas vezes, com o que é discutido no campo acadêmico-educacional.

\footnotetext{
${ }^{1}$ O Programa Nacional do Livro Didático (PNLD) é, atualmente, um programa voltado à avaliação, aquisição e distribuição de obras didáticas aos estudantes de escolas públicas brasileiras. Após a avaliação das obras, que ocorre a cada três anos, o Ministério da Educação (MEC) publica o Guia de Livros Didáticos com resenhas das coleções aprovadas, que é disponibilizado às escolas a fim de subsidiar a escolha dos livros que serão usados em sala de aula.
} 
Em uma pesquisa com 12 professoras de $3^{\mathrm{a}}$ e $4^{\mathrm{a}}$ séries da rede pública municipal de Recife, capital do estado de Pernambuco, Brasil, Morais (2002) constatou, por meio da realização de entrevistas, que os depoimentos dessas docentes revelavam tentativas evidentes de inovação, que se expressavam no estudo de aspectos normativos atrelados ao texto, prazeroso e na negação da transmissão de regras e categorias gramaticais desvinculadas dos textos. Apesar disso, os temas ou objetos tratados como conhecimentos linguísticos, nas aulas, tendiam a concentrar-se nos velhos conteúdos da gramática escolar tradicional.

Segundo Mendonça (2006, p. 201), “atravessamos um momento especial, em que convivem 'velhas' e 'novas' práticas no espaço da aula de gramática, por vezes, conflituosas". A fim de compreender melhor esse momento, apoiamo-nos, também, em discussões sobre os saberes e as práticas docentes, por entendermos que tais reflexões são fundamentais para a compreensão das mudanças nas maneiras de ensinar no cotidiano da sala de aula.

\section{Os professores, seus saberes e suas práticas}

Embora as discussões teóricas sobre o ensino de língua materna apresentadas anteriormente tenham se tornado, no Brasil, de certo modo, hegemônicas, é preciso reconhecer que as mudanças nas práticas de ensino não ocorrem de maneira automática, como resultado direto de mudanças produzidas no campo teórico. Nessa perspectiva, compreendemos que os docentes não simplesmente reproduzem os conhecimentos a que tem acesso, mas antes os reelaboram, recriam e reinventam em seu trabalho cotidiano.

Compreendendo que os saberes da ação não são fruto de uma transmissão, mas de uma apropriação e de uma produção, Weisser (1998) esclarece que os professores transformam os discursos científicos estabelecidos, tendo em vista a constituição progressiva de um repertório de gestos profissionais, que resultam de influências múltiplas.

Nessa ótica, autores como Chartier $(1998,2000)$ e Tardif (2011), apontam que os professores reconstroem e adequam ao seu trabalho cotidiano os conhecimentos e as informações a que têm acesso, por meio de diferentes fontes (cursos, livros, revistas etc.), mantendo apenas aqueles que podem ter um valor de uso para eles.

Chartier (1998, 2000), por exemplo, defende que as inovações didáticas são escolhidas, testadas, mantidas ou abandonadas pelos professores não a partir de critérios validados cientificamente, mas tomando como referência o seu uso em sala de aula. Desse modo, as inovações são incorporadas apenas quando contribuem para uma melhor organização do trabalho pedagógico. Caso contrário, são adaptadas ou mesmo descartadas, principalmente quando envolvem um aumento de trabalho e uma perda de eficiência.

Nessa mesma linha, Tardif (2011) esclarece que os professores retraduzem a sua formação e a ajustam ao seu trabalho cotidiano, eliminando o que parece inútil ou sem relação com a realidade vivida, e conservando apenas o que pode servir de alguma maneira. Desse 
modo, esse autor compreende que é a experiência e não a teoria que (in)valida os saberes adquiridos anteriormente ao exercício da prática docente cotidiana ou fora dela.

Concordando com esses autores, entendemos que a lógica do professor não é e nem poderia ser a mesma do cientista/pesquisador. Isto é, é preciso não confundir coerência teórica ou racionalidade científica com coerência pragmática ou racionalidade docente, que está ligada à ação do professor e é sempre adequada às situações práticas de exercício do seu trabalho (CHARTIER, 1998; TARDIF, 2011). Isso significa que o professor possui, sim, uma racionalidade, mas que é distinta, mas não menos importante, que a da ciência.

Por outro lado, alguns autores, como Perrenoud (1997), apontam que os professores não têm consciência de tudo o que fazem em sala de aula. Segundo esse autor, apesar de a prática pedagógica ser apresentada como sendo mais consciente e racional do que é na verdade, muitas das ações docentes não estão sob o controle da razão e da escolha deliberada. Chartier $(2005$, p.24) também ressalta que esses saberes da ação "permanecem, a maior parte do tempo, invisíveis e desconhecidos dos próprios indivíduos que os praticam", mas não são, de modo algum, irracionais, ainda que não se inscrevam na lógica da racionalidade discursiva.

Considerando tais discussões, assumimos, portanto, a perspectiva de que os saberes e os fazeres do professor não são resultado de uma transposição didática direta de conhecimentos, seja do âmbito teórico, seja do âmbito das produções a ele diretamente dirigidas, mas, sim, decorrência de um complexo processo de apropriação que os pesquisadores precisam melhor compreender.

\section{Aspectos metodológicos do estudo}

Considerando a natureza do nosso objeto de estudo, adotamos uma abordagem qualitativa de pesquisa, que, de acordo com Minayo (2011), se ocupa do universo de significados, motivos, aspirações, crenças, valores e atitudes. No entanto, por entendermos, assim como essa autora, que não existe dicotomia entre qualidade e quantidade, recorremos também a dados quantitativos.

A pesquisa que desenvolvemos foi realizada com professores que atuavam no primeiro segmento do ensino fundamental, pois, embora o ensino de gramática se materialize de modo mais evidente nos anos posteriores desse segmento escolar, é inegável que a tradição gramatical começa se instalar nas escolas brasileiras logo após a etapa da alfabetização inicial, quando os alunos são iniciados em aulas de gramática. Após alguns contatos iniciais, dispuseram-se a participar da pesquisa 8 (oito) professores que ministravam aulas em turmas de $4^{\circ}$ ou $5^{\circ}$ ano do ensino fundamental de escolas públicas de secretarias de educação de cidades do interior do estado de Pernambuco - Brasil, os quais são caracterizados no Quadro 1 , apresentado a seguir. 
Quadro 1 - Caracterização dos professores participantes da pesquisa

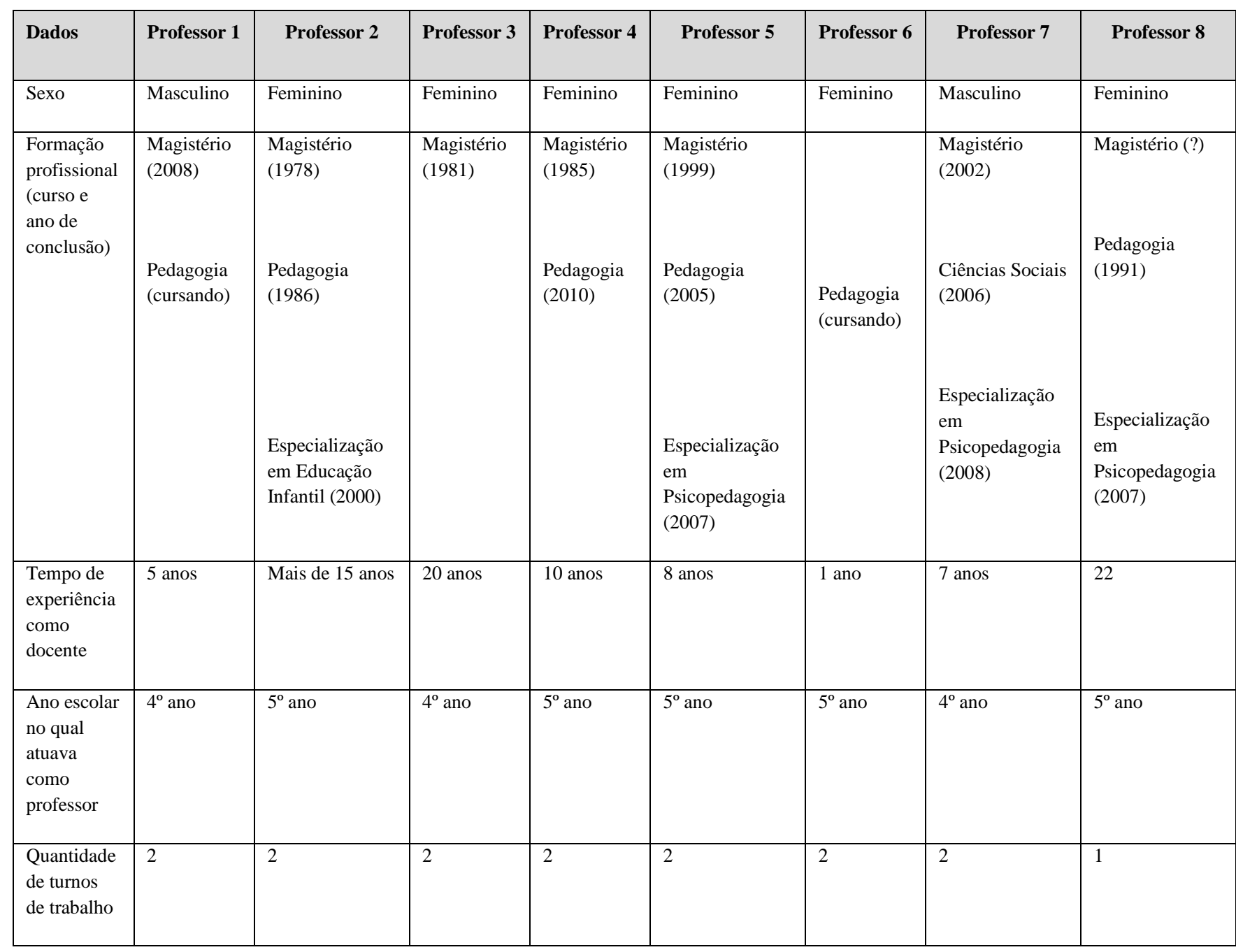

Os dados do Quadro 1 evidenciam que, dos 8 (oito) professores participantes da pesquisa, apenas 2 (dois) eram do sexo masculino. Quanto à formação profissional, todos tinham habilitação para o magistério nos primeiros anos do ensino fundamental, seja em nível médio (magistério), seja em nível superior (pedagogia). Como exceção do professor 3, todos tinham (ou estavam realizando) formação universitária em cursos de graduação ou pósgraduação lato sensu (especialização).

Com relação à experiência docente, metade dos professores tinha 10 (dez) ou mais anos de atuação como professores, o que demonstra uma experiência considerável na docência. A outra metade contemplava um professor iniciante, com apenas um ano de experiência, e três docentes que tinham 7,8 e 5 anos de trabalho, respectivamente. Dos 8 (oito) docentes, 3 (três) ensinavam em turmas do $4^{\circ}$ ano e 5 (cinco) em turmas do $5^{\circ}$, e todos, excetuando o professor 8 , trabalhavam em dois turnos. 
Para analisar mudanças nas práticas de ensino de gramática/análise linguística, utilizamos, como procedimentos metodológicos, a entrevista semiestruturada e a observação participante. No entanto, em virtude dos limites espaciais deste artigo, apresentamos, neste trabalho, apenas os resultados relativos às entrevistas semiestruturadas realizadas com os docentes.

As entrevistas semiestruturadas consistem, segundo Laville e Dione (1999), em uma série de perguntas verbais abertas, em uma ordem prevista, na qual o entrevistador pode acrescentar perguntas de esclarecimento. Essas entrevistas, que foram realizadas com o apoio de gravação em áudio, tiveram como objetivo obter informações sobre a formação e experiência profissional dos professores e, principalmente, sobre suas práticas de ensino de gramática/análise linguística.

Essa entrevista abordou tópicos como: mudanças no modo de ensinar gramática/análise linguística; objetivos desse ensino; articulação entre gramática/análise linguística e leitura e produção de textos; conteúdos de gramática/análise linguística ensinados; ensino de classificações e nomenclaturas gramaticais; uso do livro didático e de outros recursos.

Os dados brutos, obtidos por meio das entrevistas, foram analisados com o apoio da análise de conteúdo, que contempla, segundo Bardin (2004), processos de descrição, inferência e interpretação. A análise foi desenvolvida por meio de recorte do conteúdo por temas (análise temática categorial) e envolveu as seguintes etapas indicadas pela autora supracitada: pré-análise, análise do material (codificação e categorização da informação) e tratamento dos resultados, inferência e interpretação.

\section{As mudanças nas práticas de ensino de gramática/análise linguística: o que disseram os professores?}

Ao analisar as entrevistas realizadas com os professores, percebemos, em suas falas, a partir do suporte da análise temática de conteúdo, que todos disseram que tinham alterado as suas maneiras de ensinar gramática/análise linguística. O que teria motivado essas mudanças? Entre os motivos citados pelos professores para tais mudanças, os mais recorrentes foram o atendimento aos alunos (facilitar a aprendizagem ou tornar o ensino mais atrativo) e a experiência em sala de aula. Outros motivos mencionados foram: disponibilidade de outros recursos didáticos; ineficácia do ensino tradicional e exigência do ministério da educação.

Mas, afinal, que mudanças eram essas que os professores disseram ter realizado em suas práticas de ensino de gramática/análise linguística? Para os docentes, essas mudanças relacionavam-se, basicamente, a dois aspectos principais: o ensino de gramática/análise linguística a partir de textos e o uso não exclusivo do livro didático. São esses dois aspectos que abordamos no próximo tópico. 


\subsection{Ensino de gramática/análise linguística a partir de textos: um novo modo de ensinar?}

Nos emblemáticos anos 1980, um discurso muito difundido entre os professores brasileiros era o de que o ensino de gramática deveria ocorrer de maneira contextualizada, sempre a partir de textos. Ao analisar como professores estavam se apropriando desse discurso, Albuquerque (2006, p. 162) observou que eles internalizavam essas orientações "considerando o que é possível e pertinente de ser feito em sala de aula, dentro de suas condições de trabalho, e reorganizam suas práticas com base nessa questão".

No caso dos professores que entrevistamos, observamos que todos mencionaram que ensinavam gramática a partir de textos. Pelos depoimentos expostos a seguir, ensinar gramática a partir de textos significava, para os docentes, de modo geral, extrair palavras e frases pertencentes a determinadas categorias gramaticais de textos. Eis alguns depoimentos:

[...] Eu trabalho determinado texto e nesse texto geralmente a gente tira determinadas coisas do conteúdo, digamos, da gramática. A gente trabalha o verbo, então, no texto, a gente vê qual é a ação, eles vão identificar os verbos desse texto. (PROF. 1)

[...] Por exemplo, se eu vou trabalhar "verbo", eu trago um determinado texto e, por exemplo, pergunto: o que o personagem está fazendo? Aí eles respondem: "Correndo!" Então vou explicar que correr é um verbo... (PROF. 3)

Como pode ser observado nessas falas, extrair de textos palavras de determinadas classes gramaticais seria, para eles, um novo modo de ensinar gramática, já que as palavras não seriam mais apresentadas isoladamente, mas retiradas de um texto. Esse novo modo de ensinar parece revelar, portanto, uma tradução do discurso que aponta a necessidade de articulação das práticas de leitura, escrita e gramática. Eis o que disse um dos professores a esse respeito: "[...] eu trabalhava gramática separada do texto e hoje eu não faço mais isso. Eu pego o texto, faço com que ele [o aluno] pesquise, que ele observe a gramática contida no texto" (Prof. 2).

O que pudemos perceber é que os docentes parecem ter incluído o texto como unidade de ensino - o que atenderia ao imperativo de mudança -, mas sem abrir mão de práticas de ensino conhecidas e consolidadas - o ensino de nomenclaturas e classificações -, que, por isso mesmo, dão mais segurança. Segundo Albuquerque (2006), o uso do texto como pretexto parecia ser também para as professoras participantes do estudo por ela desenvolvido uma nova forma de ensinar os conteúdos antigos (ortografia e gramática).

Como observam diferentes autores (MENDONÇA, 2006; MORAIS; SILVA, 2007), esse novo procedimento - retirar palavras e frases de textos - evidencia, na realidade, a manutenção do antigo ensino tradicional de gramática, pois a única diferença é que, em vez de partir de palavras ou frases isoladas, como acontecia no chamado ensino tradicional, partese agora de textos, que são usados como pretexto para o ensino de gramática. 
Embora tenha dito que agora também ensinava gramática a partir de textos, um dos docentes (professor 3) afirmou, explicitamente, que não havia alterado radicalmente as suas práticas de ensino de gramática. Quando explicitou como realizava seu trabalho, essa docente disse que usava textos para explorar tópicos gramaticais, mas que também gostava de ensinar de um modo mais tradicional, mais direto, apresentando definições. Quando questionada sobre tal opção, disse que essa prática de ensino seria menos complicada para os alunos compreenderem, uma vez que tinha muitos alunos e a maioria tinha dificuldade de prestar atenção às explicações. Eis o depoimento da professora:

[...] Eu sempre procuro extrair de algum texto o assunto que eu vou trabalhar, peço para os alunos ler e vou ajudando eles a identificarem o assunto que eu vou trabalhar. [Como assim?] Por exemplo... Se eu vou trabalhar "verbo", eu trago um determinado texto e, por exemplo, pergunto: o que o personagem está fazendo? Aí eles respondem: Correndo! Então vou explicar que correr é um verbo. Mas eu gosto também de colocar a definição do assunto no quadro. Eu gosto de trabalhar de uma maneira mais tradicional, mais direta. [Por quê??] Ah, porque é menos complicado para os alunos compreenderem. São muitos alunos e a maioria deles tem dificuldade de prestar atenção na explicação. Por isso eu gosto de ser mais direta (PROF. $3)$.

Inspirando-nos em Chartier (1998), interpretamos que esse dado parece evidenciar que a preferência dessa professora por um ensino mais tradicional, mais direto devia-se não a razões de ordem teórica, mas a uma maior facilidade de desenvolvimento de seu trabalho pedagógico. Esse dado encontra, assim, respaldo no conceito de coerência pragmática desenvolvido pela autora supracitada, o qual se relaciona ao atendimento das demandas do cotidiano da sala de aula.

O outro aspecto ao qual os professores se referiram como representando uma mudança em suas práticas de ensino de gramática de gramática/análise linguística consistia no uso não exclusivo do livro didático. É sobre esse tema que discutimos a seguir.

\subsection{0 (não) uso do livro didático nas aulas de gramática/análise linguística}

Embora ainda exista, em diferentes instâncias, um controvertido debate acerca do livro didático, esse recurso constitui, sobretudo a partir do século XIX, provavelmente, um dos materiais mais usados em sala de aula. Batista e Costa Val (2004) chamam a atenção para o fato de que, por apresentarem tanto uma seleção de conteúdos quanto uma proposta de transposição didática, o livro didático pode exercer influência sobre o que se ensina e sobre como se ensina.

Quanto ao uso do livro didático, percebemos que os docentes que entrevistamos apresentaram posturas divergentes. Mais da metade deles disse utilizar pouco ou muito pouco o livro adotado em sala de aula, e apresentaram as seguintes justificativas para esse pouco uso: complexidade do livro, inclusive para eles próprios, o qual apresentava textos longos e 
difíceis e/ou excesso de informação (professores 1 e 3); distanciamento da realidade dos alunos e/ou pouca atratividade para eles (professores 1 e 7); presença (professor 5) ou ausência (professores 3 e 8) de abordagem tradicional no livro. Eis o que disseram alguns docentes:

Os textos que esses livros trazem são enormes e difíceis para os alunos compreenderem. Até pra gente que é professor fica difícil, imagina para eles! Eu sempre trago as atividades e os textos de casa. Eu gostava mais dos livros de antigamente: eles eram mais tradicionais, os alunos compreendiam melhor (PROF. 3).

Porque esse livro traz mais... Aliás, os livros atuais eles não trazem muito a gramática, como eram os livros antigos. Então, nesse daí, a gente utiliza mais interpretação de texto, tem muita leitura, mas a gramática trazendo o que é isso, se é assim, se usa desse jeito, não. Aí, a gente tem que ir à procura. Às vezes, a gente passa trabalho pra eles trazerem alguma informação, mas o livro mesmo, na maioria, hoje, não traz a gramática (PROF. 8).

A outra parte dos professores entrevistados disse, contrariamente, que utilizava o livro didático em sala de aula, pois consideravam os seus conteúdos e atividades importantes (docente 4), atualizados e adequados (professor 2) e coerentes com o plano de ensino para o ano letivo (professor 6), conforme podemos observar nos depoimentos a seguir:

Utilizo. [...] Tá bem atualizado. O livro traz bons exercícios, textos, gramática que dá pra gente trabalhar com o aluno (PROF. 2).

[...] eu utilizo ele e diversos outros livros. E sobre as atividades apresentadas por ele, são conteúdos que "batem" de acordo com o planejamento anual (PROF. 6).

Apesar da divergência quanto ao uso dos livros didáticos, os professores foram unânimes quando disseram que não se limitavam ao uso desse recurso e recorriam a outros materiais, que incluíam não apenas outros livros didáticos, como também diferentes tipos de material impresso, como revistas, jornais, dicionário, cartaz e livro paradidático. Esse dado evidencia, portanto, que os docentes não se limitariam ao uso do livro didático, o que, para eles, representa, como já dissemos, uma mudança em relação às práticas tradicionais de ensino.

Esse aspecto - o uso não exclusivo do livro didático - pode ser evidenciado, de modo exemplar, nas seguintes falas de um dos docentes (professor 1), que, reiteradas vezes, disse não se limitar ao uso desse recurso em sala de aula e recorrer a outros materiais. $\mathrm{O}$ uso exclusivo do livro didático parece, para esse docente, estar nitidamente relacionado a uma prática de ensino tradicional. Eis o seu depoimento:

[...] Geralmente, eu trago outros textos, não com ele [o livro didático], assim... Eu trabalho [com o livro didático], só que nem tanto. Geralmente, eu trago mais texto de suporte, textos fatiados, textos que não tão dentro de livro. Eu já trago xerocado. [...] Não que eu me pegue totalmente ao livro, eu trago mais outras coisas, outros recursos (PROF.1). 
É interessante ressaltar que esse docente, apesar de haver dito que utilizava pouco ou muito pouco o livro adotado em sala de aula, recorria a outros livros didáticos de apoio não aprovados pelo Programa Nacional do Livro Didático - $\mathrm{PNLD}^{2}$ que eram mais próximos de uma perspectiva tradicional. Esses dados parecem demonstrar, conforme observou Lerner (2004, p. 117), que "os professores escolhem livros que lhes garantam certa segurança, porque confirmam seu saber-fazer e estão de acordo com uma lógica escolar estabelecida (sem levar em conta a qualificação que deles possam fazer-se no Guia)". Nesse sentido, uma dos docentes (professor 3), a mesma que havia dito que gostava de ensinar de modo mais tradicional, também comentou, como podemos observar em um dos depoimentos apresentados anteriormente, que preferia os livros didáticos antigos, pois os alunos compreendiam melhor os conteúdos e atividades. Outra docente (professor 8), conforme vimos, também revelou essa mesma preferência, pois, segundo ela, os atuais livros didáticos não trazem muito a gramática.

\section{Algumas considerações finais}

Este trabalho consistiu em uma investigação sobre mudanças no ensino de gramática/análise linguística em um contexto de radicais mutações teóricas, mas que não tinha a intenção de estabelecer uma relação direta e mecânica entre essas mudanças e aquelas produzidas nas práticas de ensino. Nesse sentido, não teve, como muitas vezes se tem, o objetivo de rotular os professores de resistentes às inovações, mas, sim, de compreender as mudanças por eles engendradas.

Os resultados deste estudo evidenciaram que, para os professores, as mudanças em suas práticas de ensino de gramática/análise linguística relacionavam-se, principalmente, a dois aspectos: a utilização de textos e o uso não exclusivo do livro didático. No entanto, tais mudanças não substituíram, inteiramente, as antigas maneiras de ensinar gramática, mas revelaram um complexo processo no qual se articulavam mudanças e permanências.

Nesse sentido, embora tenham declarado que agora ensinavam gramática a partir de textos, os professores recorriam a eles, na realidade, como pretexto para o antigo ensino de tópicos gramaticais. Quanto ao não uso exclusivo do livro didático, constatamos que esse não uso poderia estar relacionado não apenas à incorporação de outros materiais, mas também à preferência por livros didáticos mais tradicionais, que, por esse motivo, estariam mais próximos do modelo de ensino ao qual os professores estão mais familiarizados.

Consideramos, assim como Tardif e Raymond (2000), que os docentes parecem manter práticas que dão certa segurança, as quais estão ancoradas, muitas vezes, em suas experiências escolares anteriores à sua formação profissional e que tendem a ser mantidas, mesmo após essa formação. Essa constatação demonstra, assim, que os saberes provenientes da formação profissional para o magistério não são suficientes, por si sós, para desbancar

${ }^{2}$ Essas informações foram obtidas por meio de observação de um conjunto de aulas desse docente. 
práticas de ensino consolidadas durante muitos anos e que, por isso mesmo, constituem um porto seguro.

Apoiando-nos em Chartier (1998, 2000), interpretamos que esses resultados não podem ser analisados do ponto de vista de uma coerência teórica, mas, sim, de uma coerência pragmática, que diz respeito à pertinência das ações docentes às diversas dimensões do trabalho pedagógico desenvolvido em sala de aula. Nesse sentido, entendemos que as inovações são, como salienta essa autora, colocadas à prova e incorporadas apenas quando contribuem para uma melhor organização do trabalho pedagógico. Caso contrário, são adaptadas ou mesmo descartadas.

Desse ponto de vista, consideramos necessário que outros estudos sobre mudanças no ensino de gramática/análise linguística contribuam para uma aproximação maior às maneiras de ensinar dos professores, indo além da simples crítica da manutenção de práticas de ensino centradas em classificações e nomenclaturas gramaticais.

\section{Referências}

ALBUQUERQUE, E. B. C. Mudanças didáticas e pedagógicas no ensino da língua portuguesa: apropriações de professores. Belo Horizonte: Autêntica, 2006.

BARDIN, L. Análise de conteúdo. 3 ed. Lisboa: Edições 70, 2004.

BATISTA A. A. G.; COSTA VAL, M. G. Livros didáticos, controle do currículo, professores: uma introdução. In: BATISTA A. A. G.; COSTA VAL, M. G. (Orgs.). Livros didáticos de alfabetização e de português: os professores e suas escolhas. Belo Horizonte: Autêntica, 2004.

CHARTIER, A-M. L'expertise enseignante entre savoirs pratiques et savoirs théoriques. Recherche et Formation, Paris, v. 1, n.27, p. 67-82, 1998.

CHARTIER, A-M. Réussite, échec et ambivalence de l'innovation pédagogique : le cas de l'enseignement de la lecture. Recherche et Formation, Paris, inserir v. 1, n. 34, p. 41-56, 2000.

CHARTIER, A-M. Escola, culturas e saberes. In: XAVIER, L. N.; CARVALHO, M. M. C.; MENDONÇA, A. V.; CUNHA, J. L. (Orgs.). Escola, culturas e saberes. Rio de Janeiro: FGV, 2005. p.9-28.

COSTA VAL, M. G. ; Castanheira, M. L. Cidadania e ensino em livros didáticos de alfabetização e de língua portuguesa (de $1^{\mathrm{a}}$ a $4^{\mathrm{a}}$ série). In: ; MARCUSCHI, E. (Orgs.). Livros didáticos de língua portuguesa: letramento e cidadania. Belo Horizonte: Autêntica, 2005. p.9-28. 
GERALDI, J. W. Unidades básicas do ensino de Português. In : (Org.). O texto na sala de aula: leitura e produção. 4 ed. São Paulo: Ática, 2003. p.57-79.

LAVILLE, C.; DIONNE, J. A construção do saber: manual de metodologia da pesquisa em ciências humanas. Porto Alegre: Artmed; Belo Horizonte: Editora UFMG, 1999.

LERNER, D. O livro didático e a transformação do ensino da língua. In: BATISTA, A. A. G.; COSTA VAL, M. G. (Orgs.). Livros didáticos de alfabetização e de português: os professores e suas escolhas. Belo Horizonte: Autêntica, 2004. p.115-136.

MARINHO, M. A Língua Portuguesa nos currículos de final de século. In: BARRETO, E. S. et al. (Orgs.). Os currículos do ensino fundamental para as escolas brasileiras. Campinas: Autores Associados; São Paulo: Fundação Carlos Chagas, 1998. p.43-90.

MATTOS E SILVA, R. V. Contradições no ensino de Português: a língua que se fala x a língua que se ensina. São Paulo: Contexto, 1997.

MENDONÇA, M. R. S. Análise linguística no ensino médio: um novo olhar, um outro objeto. In: BUNZEN, C.; MENDONÇA, M. (Orgs.). Português no ensino médio e formação do professor. São Paulo: Parábola, 2006. p.197-226.

MINAYO, M. C. S. O desafio da pesquisa social. In . (Org.) Pesquisa social: teoria, método e criatividade. 30 ed. Petrópolis: Vozes, 2011. p. 19-29.

MORAIS, A. G.; SILVA, A. Produção de textos escritos e análise linguística na escola. In: LEAL, T. F.; BRANDÃO A. C. P. (Orgs.). Produção de textos na escola: reflexões e prática no Ensino Fundamental. Belo Horizonte: Autêntica, 2007. p.135-150.

MORAIS, A G. Monstro à solta ou... “Análise Linguística” na escola: apropriações de professoras das séries iniciais ante as novas prescrições para o ensino de "Gramática". In: REUNIÃO ANUAL DA ANPED, 28, 2002, Rio de Janeiro. Anais... Rio de Janeiro: ANPED, 2002. Inserir p.1-16. CD.

NEVES, M. H. M. Que gramática estudar na escola? São Paulo: Contexto, 2003.

NEVES, M. H. M. A gramática passada a limpo: conceitos, análises e parâmetros São Paulo: Parábola, 2012.

PERRENOUD, P. Práticas pedagógicas, profissão docente e formação: perspectivas sociológicas. Lisboa: Dom Quixote, 1997.

SOARES, M. Concepções de linguagem e o ensino da Língua Portuguesa. In: N. B. Bastos (Org.). Língua Portuguesa: história, perspectivas, ensino. São Paulo: EDUC, 1998. p.53-60. 
TARDIF, M. Saberes docentes e formação profissional, 12 ed. Petrópolis: Vozes, 2011.

TARDIF, M.; RAYMOND, D. Saberes, tempo e aprendizagem do trabalho no magistério.

Educação e Sociedade, Campinas, v. 21, n.73, p.209-244, dez. 2000.

WEISSER, M. Le savoir de la pratique: l'Existence précède l'Essence... Recherche et Formation, v. 1, n.27, p.93-102. 1998.

Recebido em: fevereiro 2014

Aprovado para publicação em: março 2015 